Article

\title{
Micellar Electrokinetic Chromatography with Laser-Induced Fluorescence Detection for Separation of Red and Yellow Historical Dyes
}

\author{
Shokoufeh Ahmadi ${ }^{1, \dagger}$, Douglas B. Craig ${ }^{2, \dagger}$ and Douglas M. Goltz ${ }^{1,2, *}$ \\ 1 Department of Chemistry, University of Manitoba, Winnipeg, MB R3T 2N2, Canada; \\ E-Mail: chemist_sh@yahoo.ca \\ 2 Department of Chemistry, Richardson College for the Environment and Science Complex, \\ University of Winnipeg, 599 Portage Ave., Winnipeg, MB R3B 2G3, Canada; \\ E-Mail: d.craig@uwinnipeg.ca
}

$\dagger$ These authors contributed equally to this work.

* Author to whom correspondence should be addressed; E-Mail: d.goltz@ uwinnipeg.ca; Tel.: +1-204-786-9748; Fax: +1-204-774-2401.

Received: 17 February 2013; in revised from: 11 March 2013 / Accepted: 12 March 2013 / Published: 27 March 2013

\begin{abstract}
In this study, the separation parameters in micellar electrokinetic chromatography (MEKC)-laser-induced fluorescence (LIF) were optimized for the separation of red and yellow historical dyes in $20 \mathrm{mM}$ borate buffer with $20 \mathrm{mM}$ sodium dodecyl sulfate (SDS). Separation conditions were optimized by changing $\mathrm{pH}$, organic modifier (methanol and acetonitrile) concentrations and applied voltage. The mixtures of dyes used in this study included four anthraquinone dyes (alizarin, purpurin, emodin and carmine) and six flavonoid dyes (luteolin, apigenin, kaempferol, quercetin, morin and myricetin). For this work, dyes were introduced electro-kinetically $(10 \mathrm{kV}$ for $5 \mathrm{~s})$ into a $50 \mathrm{~cm}$ capillary (10 $\mu \mathrm{m} \mathrm{id)} \mathrm{and} \mathrm{separated} \mathrm{using} \mathrm{a} \mathrm{running} \mathrm{potential} \mathrm{of} \mathrm{18,} \mathrm{20,} 22$ and $25 \mathrm{kV}$. Absolute limits of detection for most of these dyes was less than $1 \mathrm{pg}$. For dyes such as alizarin, improved detection limits were achieved at $\mathrm{pH}=9.24$; however dyes such as purpurin had significantly improved detection limits at $\mathrm{pH}=8.0$. The successful extraction and identification of a number of dyes in plants and textiles samples is also described.
\end{abstract}

Keywords: micellar electrokinetic chromatography (MEKC); laser-induced fluorescence (LIF); anthraquinone; flavonoid; historical dyes 


\section{Introduction}

The application of dyestuffs dates back more than 10,000 years to when people began using natural colorants to decorate ornamental objects, such as shells or feathers [1]. Dyestuffs can be divided by their origin (animal or plant based), color, application method (direct, mordant and vat dyes) or chemical structure. Chemically, dyes can be divided into four groups: anthraquinones, flavonoids, indigoids and tannins [2]. Of these classes, the anthraquinones and flavonoids provide numerous compounds that are structurally similar and have been used historically in paint and textile materials. The anthraquinones and flavonoids are two important classes of dyes used widely in historical objects, including textiles and paintings.

Anthraquinone dyes, shown in Figure 1(a), are typically red in appearance and are plant or animal based dyes. Dyes can be found in many types of textile objects, as they have a tendency to resist photo-fading [3]. Examples of plant-based anthraquinones are found in the madder root (Rubia tinctorum) and rhubarb (Rheum rhabarbarum). The dyes in madder consist primarily of alizarin and purpurin, while the dyes in rhubarb consist of emodin. Cochineal and kermes dyes are examples of animal-based anthraquinones. Cochineal dyes are derived from the cochineal insect and consist of carminic acid. The lake form of carminic acid is commonly known as carmine and is often prepared using aluminum and calcium salts. Kermes is derived from the insect Kermes vermilio and consists of kermesic acid, which is carminic acid aglycone [4].

Flavonoid dyes, shown in Figure 1(b), can be divided into two main groups: flavones and flavonols. Relative to anthraquinones and indigoids, flavonoids are more prone to photochemically induced fading [5] and among the flavonoids, the flavonols tend to be less resistant to fading than flavones. Examples of flavone-based yellow dyes are weld and dyer's Broom, which are rich sources of luteolin and apigenin, respectively. Old fustic, Persian berries and walnut are examples of sources for flavonol dyes. Old fustic consists of morin and kaempferol. Persian berries are a good source for quercetin and kaempferol, while walnut is a rich source of myricetin [4,6].

Figure 1. (a) The structure of anthraquinones and the position of the substituted group.

(b) The structure of flavones, flavonols and the position of the substituted group.

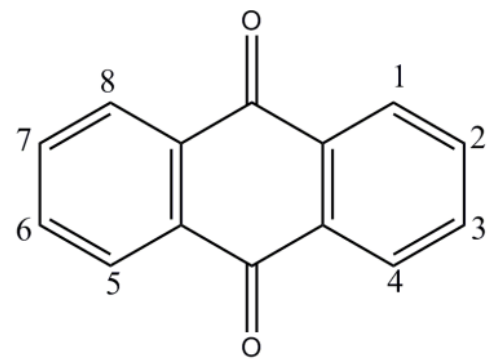

$\begin{array}{lllllllll} & 1 & 2 & 3 & 4 & 5 & 6 & 7 & 8 \\ \text { alizarin } & \mathrm{OH} & \mathrm{OH} & \mathrm{H} & \mathrm{H} & \mathrm{H} & \mathrm{H} & \mathrm{H} & \mathrm{H} \\ \text { purpurin } & \mathrm{OH} & \mathrm{OH} & \mathrm{H} & \mathrm{OH} & \mathrm{H} & \mathrm{H} & \mathrm{H} & \mathrm{H} \\ \text { emodin } & \mathrm{OH} & \mathrm{H} & \mathrm{OH} & \mathrm{H} & \mathrm{H} & \mathrm{CH}_{3} & \mathrm{H} & \mathrm{OH} \\ \text { carmine } & \mathrm{CH} & \mathrm{COOH} & \mathrm{OH} & \mathrm{H} & \mathrm{OH} & \mathrm{OH} & \text { Glucose } & \mathrm{OH}\end{array}$

(a) 
Figure 1. Cont.

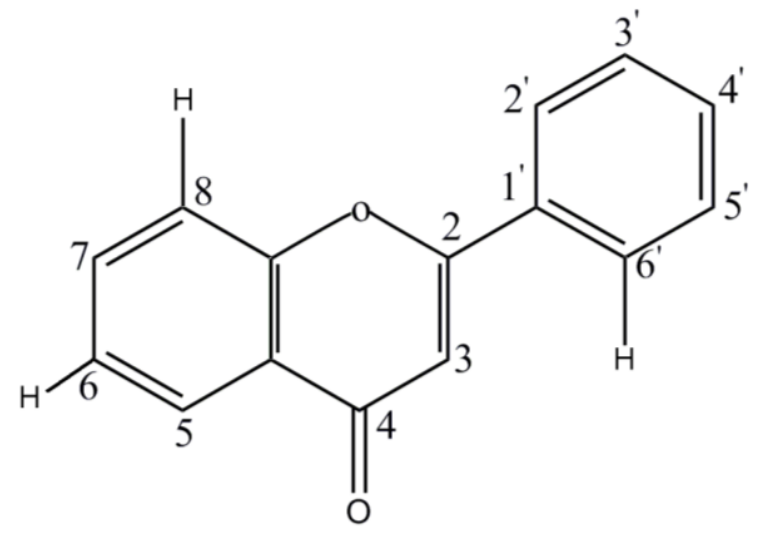

$\begin{array}{llllllll} & 3 & 5 & 7 & 2^{\prime} & 3^{\prime} & 4^{\prime} & 5^{\prime} \\ \text { Apigenin } & \mathrm{H} & \mathrm{OH} & \mathrm{OH} & \mathrm{H} & \mathrm{H} & \mathrm{OH} & \mathrm{H} \\ \text { Luteolin } & \mathrm{H} & \mathrm{OH} & \mathrm{OH} & \mathrm{H} & \mathrm{OH} & \mathrm{OH} & \mathrm{H} \\ \text { Kaempferol } & \mathrm{OH} & \mathrm{OH} & \mathrm{OH} & \mathrm{H} & \mathrm{H} & \mathrm{OH} & \mathrm{H} \\ \text { Myricetin } & \mathrm{OH} & \mathrm{OH} & \mathrm{OH} & \mathrm{H} & \mathrm{OH} & \mathrm{OH} & \mathrm{OH} \\ \text { Quercetin } & \mathrm{OH} & \mathrm{OH} & \mathrm{OH} & \mathrm{H} & \mathrm{OH} & \mathrm{OH} & \mathrm{H} \\ \text { Morin } & \mathrm{OH} & \mathrm{OH} & \mathrm{OH} & \mathrm{OH} & \mathrm{H} & \mathrm{OH} & \mathrm{H}\end{array}$

(b)

A number of instrumental approaches have been used to identify and characterize dyes in historical objects. These include ultraviolet-visible (UV-Vis) reflectance spectroscopy [7-10], Fourier transform infrared spectroscopy [11-13] and Raman spectroscopy $[14,15]$. The lack of specificity and the poor sensitivity of these approaches make them less than ideal for detecting small quantities of dye. A number of separation techniques have also been explored, and these include: thin layer chromatography (TLC) [16,17], high performance liquid chromatography (HPLC) [18,19], gas chromatography (GC) [20] and capillary electrophoresis (CE) [21-26]. High performance liquid chromatography is a common technique for separation of dyes and can be equipped with many different detection schemes, including UV-Vis and fluorescence detection, photodiode array (DAD) and mass spectrometry (MS). Gas chromatography (GC) has also been investigated; however, many dyes need to be derivatized, as they are often large, polar molecules [27].

The separation of dyestuffs has also been achieved using capillary electrophoresis (CE), and relatively few manuscripts have been published using this technique for investigating historical objects. Puchalska [21] used CE coupled with diode-array detection (DAD) and electrospray mass spectrometric (ESI-MS) detection to isolate and identify anthraquinone dyes. The separation of anthraquinones and flavonoids using CE with MS detection has been described by Surowiec [22]. Capillary electrophoresis using micelles or micellar electrokinetic chromatography (MEKC) has been described for the separation of anthraquinones and flavonoids [23]. Maguregui [24] reported the separation of red dyes using MEKC. The separation of mixtures of red, yellow and blue dyes using MEKC has also been described [25]. Relatively few studies have been reported on the use of CE with laser-induced fluorescence (LIF). Our interest in using MEKC with LIF for detection is driven by the 
need to develop minimally destructive methods for identifying dyes in historical objects, such as textiles. The most important advantage of using LIF is that the low detection limits and high sensitivity allow for the separation of very small quantities of sample, which makes this approach suitable for working with valuable historical objects. In previous work, we explored the feasibility of using CE-LIF on a small number of dyes, including purpurin and alizarin [26]. The objective of this study was to examine the feasibility of using MEKC with LIF for the separation of selected anthraquinone and flavonoid dyes. In this work, we report on some of the separation properties that affect both the fluorescence and separation properties of these dyes.

\section{Experimental Section}

Separations were carried out using a laboratory-constructed CE instrument equipped with a post-column laser-induced fluorescence detection system [28]. The injection end of a $50 \mathrm{~cm}$ long, $10 \mu \mathrm{m}$ inner diameter fused silica capillary (Polymicro Technologies, Phoenix, AZ, USA) along with a Pt electrode connected to a high voltage supply (Spellman model CZE 2000, Hauppauge, NY, USA), was placed into a buffer-filled vessel. The applied voltage across the capillary was typically 18, 20, 22 and $25 \mathrm{kV}$. The detection end of the capillary, from which a $1 \mathrm{~mm}$ length of the external polyimide coating was removed by flame, was inserted into a quartz sheath flow cuvette with a 250 by $250 \mu \mathrm{m}$ inner bore (Hellma Ltd., Concord, ON, Canada). The system was grounded through the sheath flow buffer within the cuvette. A diode laser (Coherent, Inc., Santa Clara, CA, USA) with a $407 \mathrm{~nm}$ output $(50 \mathrm{~mW})$ was employed. Light from the laser was focused with a $6.3 \times$, N.A. 0.2 microscope objective (Melles Griot, Irvine, CA, USA), approximately $10 \mu \mathrm{m}$ below the detection end of the capillary. Emission was collected at $90^{\circ}$ using a 60×, N.A. 0.7 microscope objective (Universe Kogaku, Oster Bay, NY, USA), passed through a 535AF45 optical filter (Omega Optical, Brattleboro, VT, USA) and a slit and then onto a photomultiplier tube (PMT, Hamamatsu model 1477, Brattleboro, VT, USA). The analog PMT signal was collected and digitized using a Pentium 4 computer through a PCI-MIO-16XE I/O board utilizing LabVIEW software (National Instruments, Austin, TX, USA) at $10 \mathrm{~Hz}$. The same board was used to control the electrophoresis voltage and PMT bias. Data was analyzed using IgorPro ${ }^{\mathrm{TM}}$ software (Instrutech, Port Washington, NY, USA).

\section{Reagents}

Dimethyl sulfoxide (DMSO), acetonitrile, sodium dodecyl sulfate (SDS) 99\% and sodium hydroxide were obtained from Sigma-Aldrich (St. Louis, MO, USA). Ethanol, methanol and isopropanol were purchased from EMD Chemicals Inc. (Gibbstown, NJ, USA), and sodium borate was obtained from Mallinckrodt (Hazelwood, MO, USA). The dyes used in this study were purchased from different suppliers. Myricetin, apigenin, morin, purpurin and kaempferol were from Sigma-Aldrich (St. Louis, MO, USA), emodin was from Acros Organics (Morris Plains, NJ, USA), and alizarin, carmine, quercetin and luteolin were from Alfa Aesar (Johnson Matthey Co., Lancastor, UK). Fluorescein (Molecular Probes Inc., Eugene, OR, USA) was diluted and used for aligning the optics of the CE-LIF. Borate buffers used in this study also contained $20 \mathrm{mM}$ SDS in Milli-Q water $(18 \mathrm{M} \Omega \cdot \mathrm{cm})$ (EMD Millipore Corporation, Billerica, MA, USA). Borate buffers with varying $\mathrm{pH}$ were prepared using different ratios of boric acid and sodium tetraborate. Care was taken to maintain a constant ionic 
strength of the buffers at different $\mathrm{pH}$ to allow the comparison of migration times of different electropherograms. For example, to prepare the buffer at $\mathrm{pH}=9.24$, only sodium borate was used, and for $\mathrm{pH}=8.0,62.57 \mathrm{mM}$ boric acid was mixed with $4.36 \mathrm{mM}$ sodium borate. All solutions were filtered using a $0.45 \mu \mathrm{m}$ poly syringe filter. Standard solutions of dyes $\left(1,000 \mu \mathrm{g} \cdot \mathrm{mL}^{-1}\right)$ were prepared by dissolving $10 \mathrm{mg}$ of powder in $10 \mathrm{~mL}$ dimethyl sulfoxide (DMSO) and diluted as required to $0.2-10 \mu \mathrm{g} \cdot \mathrm{mL}^{-1}$ with buffer. An organic solvent was also added to the borate buffer to enhance peak shape. A number of organic solvents were examined as modifiers including: methanol, acetonitrile, isopropanol, ethanol and dimethyl sulfoxide. All solutions were centrifuged prior to CE separation.

\section{Results and Discussion}

In order to assign fluorescence peaks to specific dyes, the elution times of individual dyes were determined separately prior to separating mixtures. To confirm the peak identity, the elution times of each dye was also determined relative to the other dyes by successively adding to or removing dyes from a known mixture. In this study, we examined the effects of organic modifiers and voltage on the separation of anthraquinone and flavonoid dyes. For the sake of brevity, only the separations of flavonoids are shown in Figures 2 and 3.

Figure 2. Separation of the flavonoid dyes: (a) $0.5 \mu \mathrm{g} \cdot \mathrm{mL}^{-1} \mathrm{kaempferol,} \mathrm{(b)} 1 \mu \mathrm{g} \cdot \mathrm{mL}^{-1}$ luteolin (c) $2 \mu \mathrm{g} \cdot \mathrm{mL}^{-1}$ apigenin, (d) $2 \mu \mathrm{g} \cdot \mathrm{mL}^{-1}$ myricetin, (e) $1 \mu \mathrm{g} \cdot \mathrm{mL}^{-1}$ quercetin, (f) $0.5 \mu \mathrm{g} \cdot \mathrm{mL}^{-1}$ morin, in $5 \%(\mathrm{v} / \mathrm{v})$ of acetonitrile or $5 \%(\mathrm{v} / \mathrm{v})$ methanol, at $18 \mathrm{kV}, 20 \mathrm{mM}$ borate buffer $(\mathrm{pH}=9.24)$ and $20 \mathrm{mM}$ sodium dodecyl sulfate (SDS).

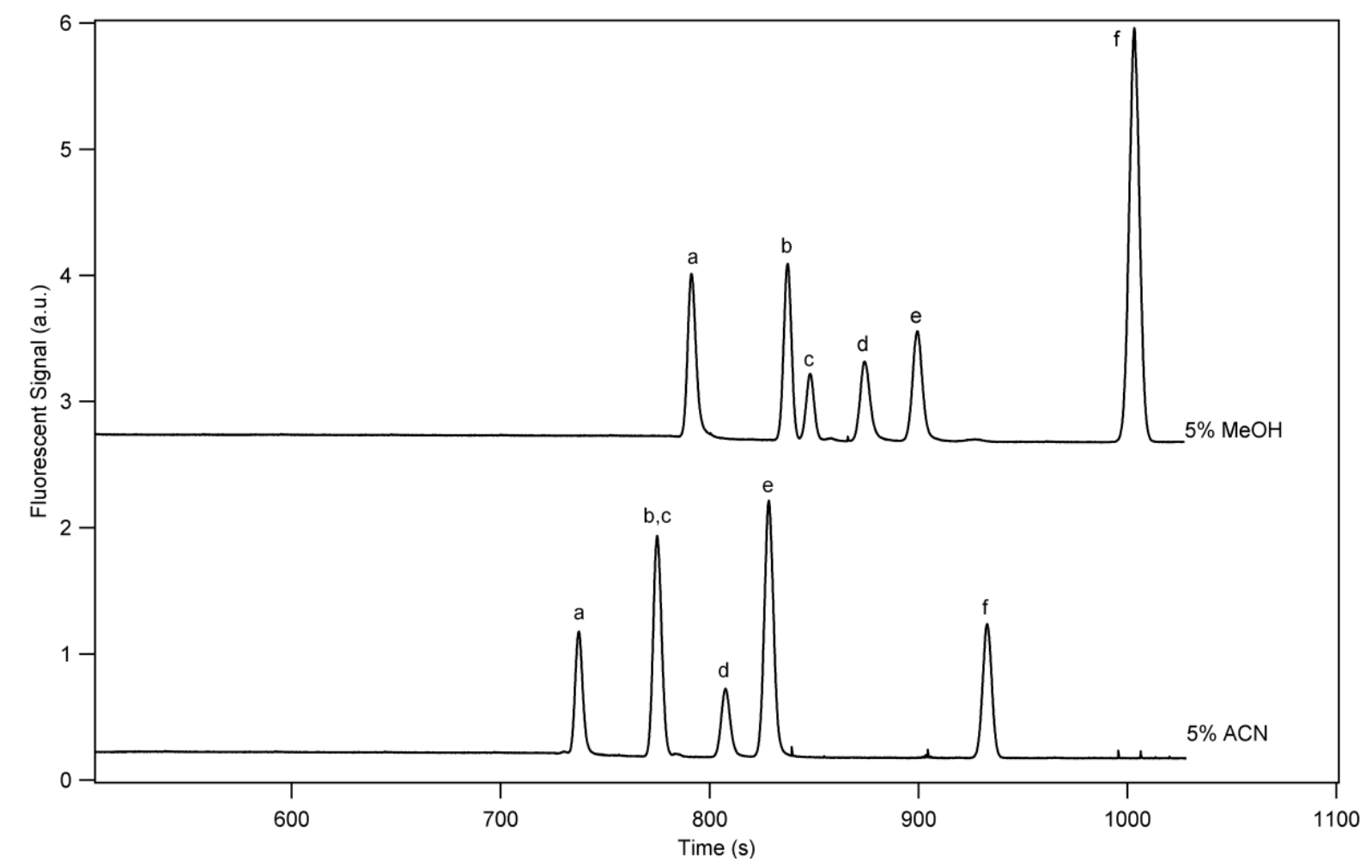


Figure 3. Separation of the flavonoid dyes (a) $0.5 \mu \mathrm{g} \cdot \mathrm{mL}^{-1} \mathrm{kaempferol,} \mathrm{(b)} 2 \mu \mathrm{g} \cdot \mathrm{mL}^{-1}$ luteolin, (c) $1 \mu \mathrm{g} \cdot \mathrm{mL}^{-1}$ apigenin, (d) $2 \mu \mathrm{g} \cdot \mathrm{mL}^{-1}$ myricetin, (e) $1 \mu \mathrm{g} \cdot \mathrm{mL}^{-1}$ quercetin, (f) $0.5 \mu \mathrm{g} \cdot \mathrm{mL}^{-1}$ morin, in $5 \%(\mathrm{v} / \mathrm{v})$ of acetonitrile, in $20 \mathrm{mM}$ borate buffer $(\mathrm{pH}=9.24)$ and $20 \mathrm{mM}$ SDS with an applied potential of 20 and $25 \mathrm{kV}$.

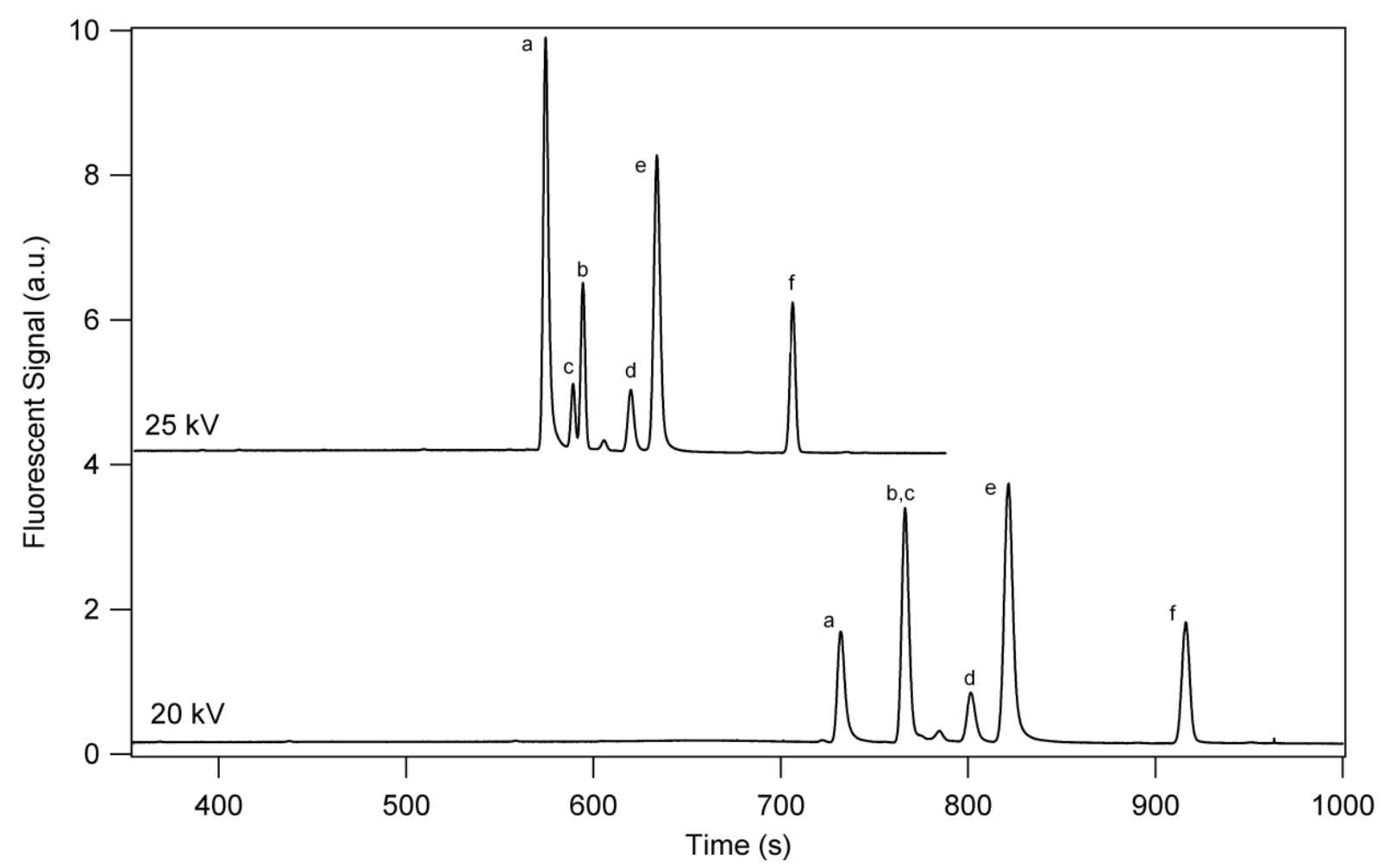

\subsection{Separation Properties}

Separations that were carried out in the absence of an organic modifier were generally not successful. The addition of organic reagents to the buffer affects viscosity, zeta potential, dielectric constant and the electroosmotic flow (EOF) [29]. Reducing the EOF can help to resolve analytes that have small differences in electrophoretic mobility [30]. McGhie et al. [31] examined the effects of methanol on the migration order of a synthetic mixture of flavonoids that includes apigenin. These authors concluded that $20 \%$ methanol gave the best separation. In this study, a number of organic solvents (methanol, ethanol, acetonitrile, dimethyl sulfoxide and isopropanol) were explored as chemical modifiers, and of these, acetonitrile and methanol gave better separations in terms of peak resolution.

Experiments were carried out to examine the effect of organic modifier concentration on the separation of these dyes using 5-20\% methanol or acetonitrile. Figure 2 shows the separation of (a) kaempferol, (b) luteolin, (c) apigenin, (d) myricetin, (e) quercetin and (f) morin in the presence of $5 \%$ acetonitrile and $5 \%$ methanol. The elution order of the dyes was consistent with data published by others groups using similar separation conditions (e.g., ionic strength) [32,33].

When higher concentrations (200 mM) of borate buffer were used, the elution order was changed [34], and the co-elution of some dyes (luteolin and myricetin; kaempferol and apigenin) resulted in poorly resolved peaks. It is also worth noting that unlike acetonitrile, the addition of methanol enabled the separation of luteolin (peak b) from apigenin (peak c). Further increases in the concentration of 
methanol at $10 \%(\mathrm{v} / \mathrm{v})$ increased the migration time of the dyes and caused the co-elution of apigenin and myricetin (not shown). Finally, with the addition of methanol or acetonitrile at concentrations up to $20 \%$, no further improvement in the peak resolution of these dyes was observed. One negative effect of adding increasing amounts of organic solvents, such as acetonitrile and methanol, was the suppression of the fluorescence signals of the dyes. Therefore, when using fluorescence detection, lower concentrations of methanol (5\%) are recommended.

The effect of applied voltage on separations can improve peak shape and reduce separation time dramatically [35]. Increasing the applied voltage in CE can also cause Joule heating of the capillary, resulting in bubble formation in the capillary or even breakage of the capillary. Since we used a $10 \mu \mathrm{m}$ capillary id, Joule heating was not a serious problem. To examine the effect of voltage, four different voltages $(18,20,22$ and $25 \mathrm{kV})$ were used for the separation of six flavonoid dyes. In these experiments, either $5 \%$ acetonitrile or $5 \%$ methanol were added to the $20 \mathrm{mM}$ borate buffer $(\mathrm{pH}=9.24)$. Figure 3 shows the separation of the selected flavonoid dyes in $20 \mathrm{mM}$ borate buffer $(\mathrm{pH}=9.24)$ using different applied voltages with $5 \%(\mathrm{v} / \mathrm{v})$ acetonitrile as a chemical modifier. In this experiment, the highest voltage $(25 \mathrm{kV})$ was the most useful for resolving luteolin (peak b) and apigenin (peak c). Similar experiments were carried out using the same applied voltages (18 and $25 \mathrm{kV}$ ) using 5\% methanol (not shown) with similar results. In the absence of an organic modifier, such as methanol or acetonitrile, increasing the applied voltage from 18 to $25 \mathrm{kV}$ did not improve the peak resolution of apigenin and luteolin.

The $\mathrm{pH}$ conditions can have dramatic effects on the separation of historical dyes in capillary electrophoresis. With increasing the $\mathrm{pH}, \mathrm{EOF}$ increases and the migration time decreases [36]. Moreover, increasing the $\mathrm{pH}$ can also affect the mobility of target analytes by deprotonating acid groups and inducing negative charges on them [37]. By changing the $\mathrm{pH}$ of the buffer, the migration time is altered by changes in the anionic charges and by changes in the distribution coefficient of the analytes between the micelles and running buffer. In general, decreasing the $\mathrm{pH}$ had the most significant effect on the more hydrophobic compounds (flavonoids) and only a slight effect on the anthraquinones. For this study, it was hypothesized that a lower $\mathrm{pH}$ buffer would significantly improve the peak shape of purpurin without compromising the separation of the other dyes.

Figure 4 shows the separation of six flavonoid dyes with a borate buffer at $\mathrm{pH}=8.0$ and different applied voltages $(18-25 \mathrm{kV})$. As expected, when compared to separations performed under similar applied voltages and similar $\mathrm{pH}$ conditions $(\mathrm{pH}=9.24)$, the migration time for all dyes decreased noticeably ( $920 \mathrm{~s} v s .630 \mathrm{~s}$ at $18 \mathrm{kV}$ ). At $\mathrm{pH}=8.0$, the hydrophobic properties of the dyes are altered, resulting in changes in the association and dissociation of dyes with the micelles [31].

In general, when a borate buffer was used at $\mathrm{pH}=8.0$, baseline separation of quercetin (e) and morin (f) was not achieved. Kaempferol (peak a) and apigenin (peak c) eluted much later than morin, with significant peak overlap at all applied potentials $(18,20$ and $25 \mathrm{kV})$. The overlapping peaks were not unexpected, given that the $\mathrm{pKa}_{1}$ values are so similar for these dyes [38-40]. Herrero-Martinez [40] reported the following $\mathrm{pKa}$ values (the numbers in parentheses refer to the position of hydroxyl group): kaempferol: 7.11 (7) and 9.09 (4'), quercetin: 7.04 (7) and 8.55 (4'), morin: 6.93 (7) and 8.32 (6'). At $\mathrm{pH}=9.24$ (Figure 2), the elution order for these dyes was: kaempferol (peak a), quercetin (peak e) and morin (peak f); but at $\mathrm{pH}=8.0$, kaempferol (peak d) and apigenin (peak c) gave two poorly resolved peaks that were shifted toward the end of the electropherogram. Increasing the applied 
potential to $25 \mathrm{kV}$ improved peak shape, but did not improve peak resolution of these dyes. Decreasing the $\mathrm{pH}$ for these separations affected the elution order of luteolin and apigenin. This effect can be explained by the changes in the flavonoid-borate complex solvation and stability of luteolin, which has two vicinal hydroxyl groups [34].

Figure 4. Separation of selected flavonoid dyes (a) $0.5 \mu \mathrm{g} \cdot \mathrm{mL}^{-1}$ kaempferol, (b) $2 \mu \mathrm{g} \cdot \mathrm{mL}^{-1}$ luteolin, (c) $1 \mu \mathrm{g} \cdot \mathrm{mL}^{-1}$ apigenin (d) $2 \mu \mathrm{g} \cdot \mathrm{mL}^{-1}$ myricetin, (e) $1 \mu \mathrm{g} \cdot \mathrm{mL}^{-1}$ quercetin, (f) $0.5 \mu \mathrm{g} \cdot \mathrm{mL}^{-1}$ morin, in $20 \mathrm{mM}$ borate buffer $(\mathrm{pH}=8.0)$ and $20 \mathrm{mM} \mathrm{SDS}$ with $5 \%$ acetonitrile and an applied potential of 18,20 and $25 \mathrm{kV}$.

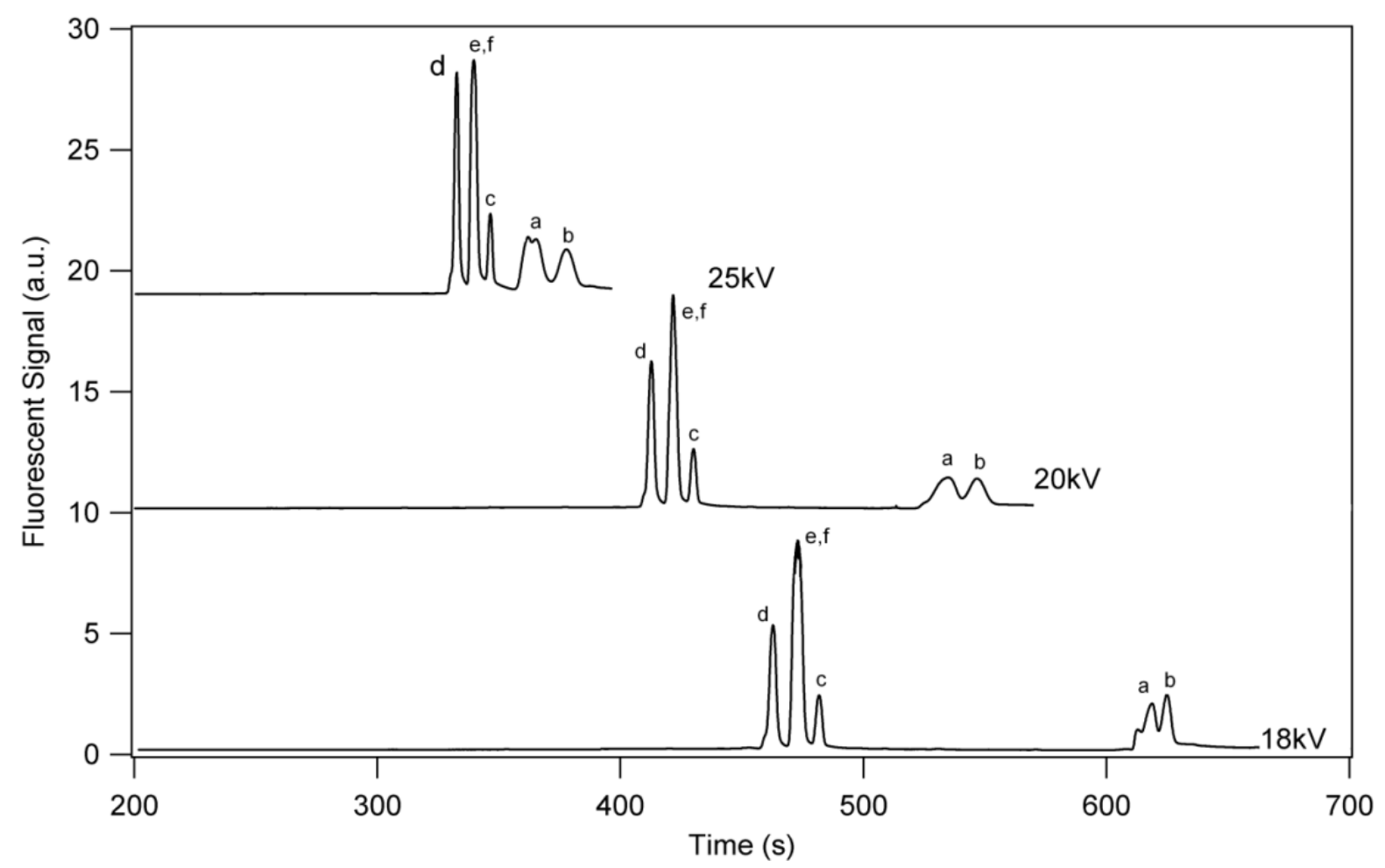

The separation of selected anthraquinone dyes was also investigated using a borate buffer at $\mathrm{pH}=8.0$. Figure 5 shows the separation of alizarin, emodin and purpurin at $\mathrm{pH}=9.24$ using an applied potential of $18 \mathrm{kV}$. For comparison, the separation of alizarin, emodin and purpurin at $\mathrm{pH}=8.0$ with an applied potential of $18 \mathrm{kV}$ and $25 \mathrm{kV}$ is also shown.

Unlike the flavonoid dyes, decreasing the $\mathrm{pH}$ of the buffer did not change the elution order of alizarin (peak a), purpurin (peak b) and emodin (peak c), possibly because these dyes are less hydrophobic. It is worth noting that at $\mathrm{pH}=8.0$, purpurin (peak b) was detected with a significantly improved peak, both in terms of shape and magnitude. Increasing the applied voltage from 18 to $25 \mathrm{kV}$ at $\mathrm{pH}=8.0$ further improved the peak shape of purpurin and provided a modest improvement in the peak resolution of these dyes. Finally, it is also worth noting that the addition of modifiers $(5 \% \mathrm{v} / \mathrm{v}$ acetonitrile or $5 \%$ methanol) at $\mathrm{pH}=8.0 \mathrm{did}$ not result in further improvements in the separation of these dyes. Clearly, changing $\mathrm{pH}$ had a significant effect on these separations, and the addition of an organic modifier or increased applied voltage did little to improve peak resolution. 
Figure 5. Separation of selected anthraquinones (a) $10 \mu \mathrm{g} \cdot \mathrm{mL}^{-1}$ alizarin, (b) $3 \mu \mathrm{g} \cdot \mathrm{mL}^{-1}$ purpurin, (c) $10 \mu \mathrm{g} \cdot \mathrm{mL}^{-1}$ emodin in $20 \mathrm{mM}$ borate buffer $(\mathrm{pH}=9.24$ and 8.0$)$ and $20 \mathrm{mM}$ SDS, using an applied potential of 18 and $25 \mathrm{kV}$.

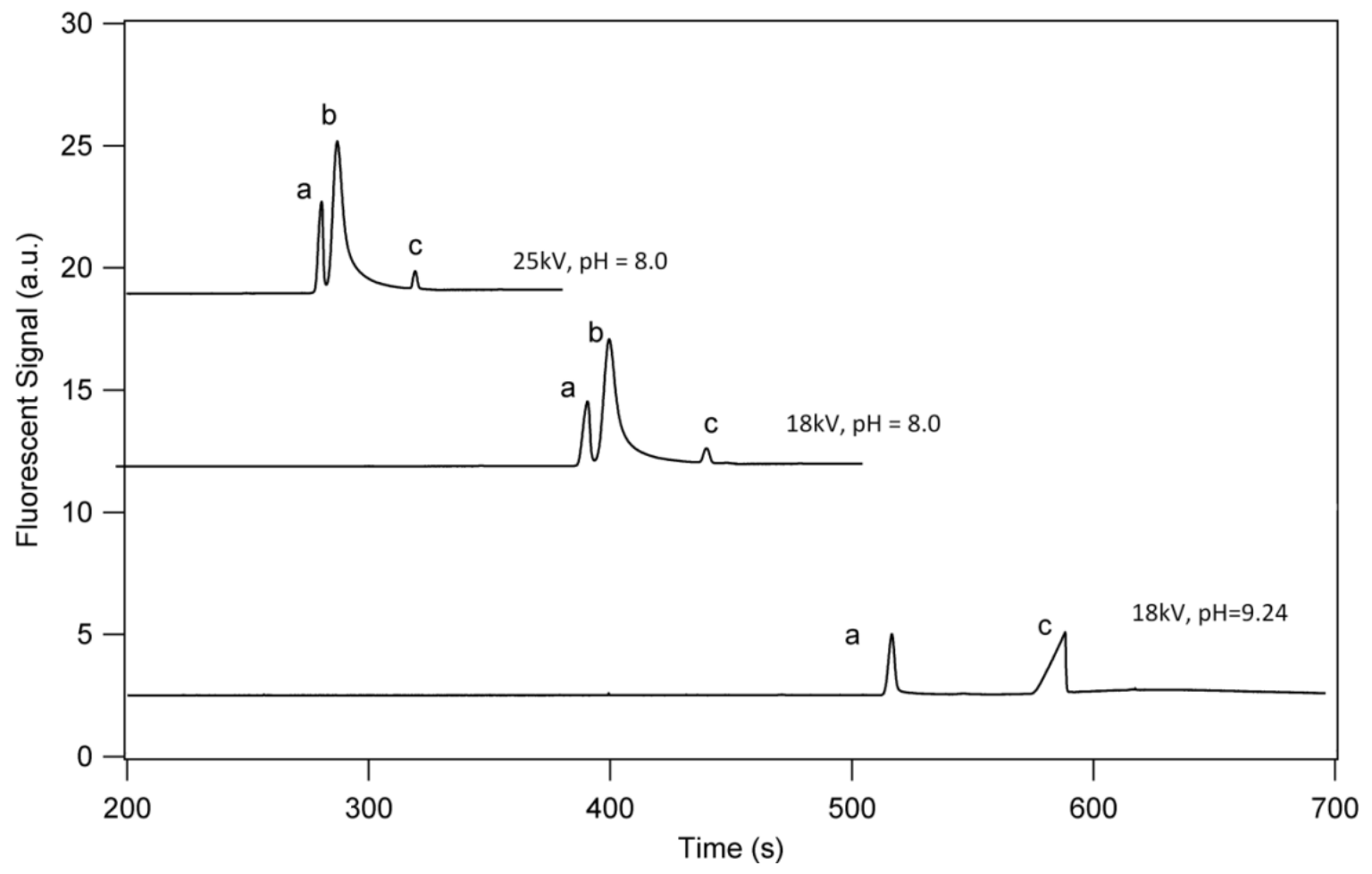

\subsection{Detection Limits}

Apart from the separation properties of the CE-LIF instrument, detection limits were also determined for these dyes. Achieving low detection limits was important for this work prior to using this approach for identifying dyes in field samples. Furthermore, because of the small sample size requirement for $\mathrm{CE}$ separations, a low detection limit is also desirable for minimizing damage to potentially valuable samples, such as museum objects. Detection limits for the dyes used in this study are shown in Table 1 under different $\mathrm{pH}$ conditions, as well as in the presence of $5 \%(\mathrm{v} / \mathrm{v})$ acetonitrile. For these separation, a $25 \mathrm{kV}$ and $20 \mathrm{mM}$ borate buffer at either $\mathrm{pH}=9.24$ or $\mathrm{pH}=8.0$ was used. Detection limits were calculated by determining $3 \mathrm{~s}$ of the background signal $(\mathrm{n}>500)$ and by comparing the magnitude of the background signal to the signal of a standard of known concentration $\left(1-10 \mu \mathrm{g} \cdot \mathrm{mL}^{-1}\right)$. Absolute detection limits (pg) were calculated by multiplying the volume injected by the concentration of the dye. The volume of each dye injected can be determined using the equation [35]:

$$
V_{\text {inj }}=V_{\text {cap }} \times\left(\frac{t_{i n j}}{t_{m}}\right) \times\left(\frac{E_{i n j}}{E_{m}}\right)
$$

where $V_{i n j}=$ volume of the sample injected (L), $V_{c a p}=$ volume of the capillary (L), $t_{i n j}=$ time that the sample was introduced in to the capillary (s), $t_{m}=$ migration time of the dye (s), $E_{i n j}=$ voltage applied for the introduction of the sample into the capillary $(V)$ and $E_{m}=$ the voltage applied for the migration of the dye in the capillary $(V)$. 
Table 1. Detection limits of selected anthraquinone dyes and flavonoid dyes.

\begin{tabular}{|c|c|c|c|c|c|c|}
\hline & \multicolumn{2}{|c|}{$\begin{array}{l}\mathrm{pH}=9.24 \\
0 \% \mathrm{ACN}\end{array}$} & \multicolumn{2}{|c|}{$\begin{array}{c}\mathrm{pH}=9.25 \\
5 \% \mathrm{ACN}\end{array}$} & \multicolumn{2}{|c|}{$\begin{array}{l}\mathrm{pH}=\mathbf{8 . 0} \\
0 \% \mathrm{ACN}\end{array}$} \\
\hline & $\mathrm{ng} \cdot \mathrm{mL}^{-1}$ & pg & $\mathrm{ng} \cdot \mathrm{mL}^{-1}$ & pg & $\mathrm{ng} \cdot \mathrm{mL}^{-1}$ & pg \\
\hline Alizarin & 14 & 0.2 & 39 & 0.9 & 70 & 2.4 \\
\hline Purpurin & ND & ND & ND & ND & 13 & 0.5 \\
\hline Emodin & 40 & 1.0 & 12 & 0.2 & 38 & 1.1 \\
\hline Kaempferol & 10 & 0.2 & 0.7 & 0.01 & 6.3 & 0.2 \\
\hline Apigenin & 23 & 0.4 & 9.0 & 0.2 & 20 & 0.5 \\
\hline Luteolin & 17 & 0.3 & 7.2 & 0.1 & 19 & 0.5 \\
\hline Carmine & ND & ND & 230 & 3.8 & 400 & 12 \\
\hline Myricetin & 51 & 0.9 & 15 & 0.2 & 5.7 & 0.2 \\
\hline Quercetin & 12 & 0.2 & 1.8 & 0.03 & 2.9 & 0.1 \\
\hline Morin & 9.0 & 0.1 & 0.7 & 0.01 & 2.4 & 0.1 \\
\hline
\end{tabular}

$\mathrm{ND}=$ not detected

For some dyes, such as alizarin and apigenin, changing the $\mathrm{pH}$ had little or no benefit. For dyes such as luteolin or purpurin, detection limits were improved significantly at $\mathrm{pH}=8.0$. The lower detection limits for these dyes at this $\mathrm{pH}$ were due to significant improvements in peak shape and an increase in peak height, without a significant change in background noise.

\subsection{Extraction of Natural Dyes in Field Samples}

The identification of dyes in a number of field samples (textiles and plants) was achieved using a simple extraction procedure. For this part of the study, small samples ( $1 \mathrm{mg}$ or less) were acquired and digested in $3 \mathrm{~N} \mathrm{HCl}$ prior to dissolution with DMSO. Separations of the dyes were carried out, and peaks were identified by comparing elution times of samples spiked with known amounts of dye.

Figure 6. Electropherograms of dyes extracted from (a) weld, (b) weld-dyed wool, (c) red brocade, (d) Persian berry, (e) madder, (f) red brocade, (g) antique cotton and (h) walnut. Separation conditions: $\mathrm{pH}=8.5 ; 20 \mathrm{mM}$ SDS with $5 \%$ acetonitrile and an applied potential of $22 \mathrm{kV}$.
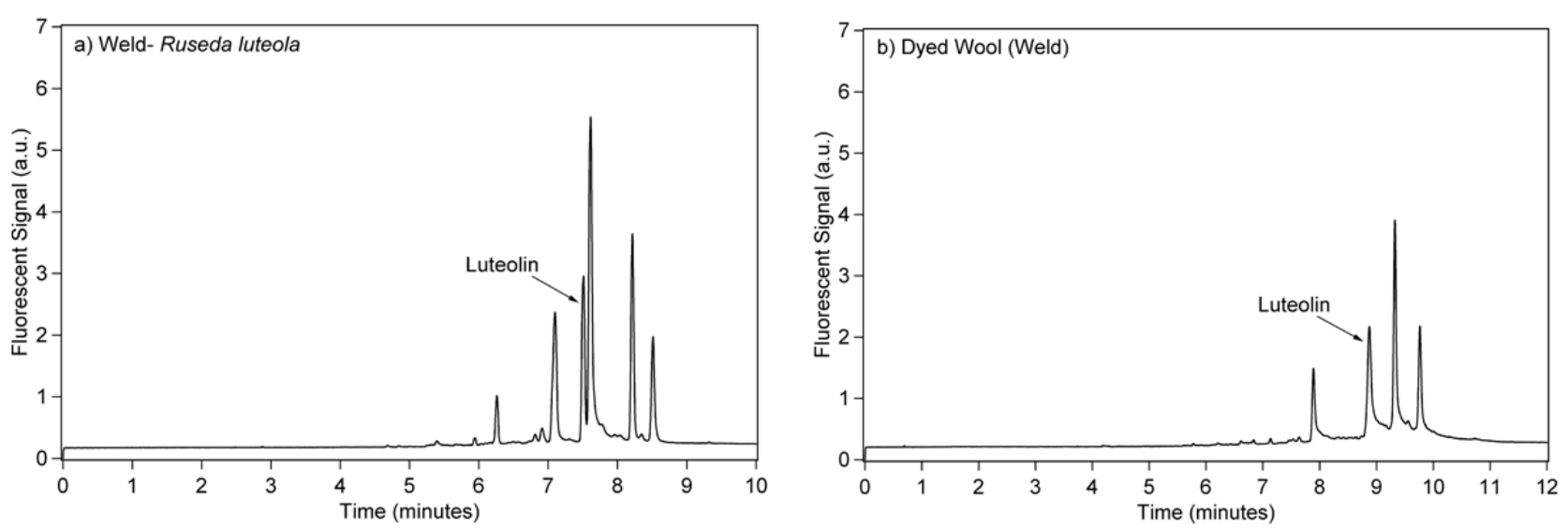
Figure 6. Cont.
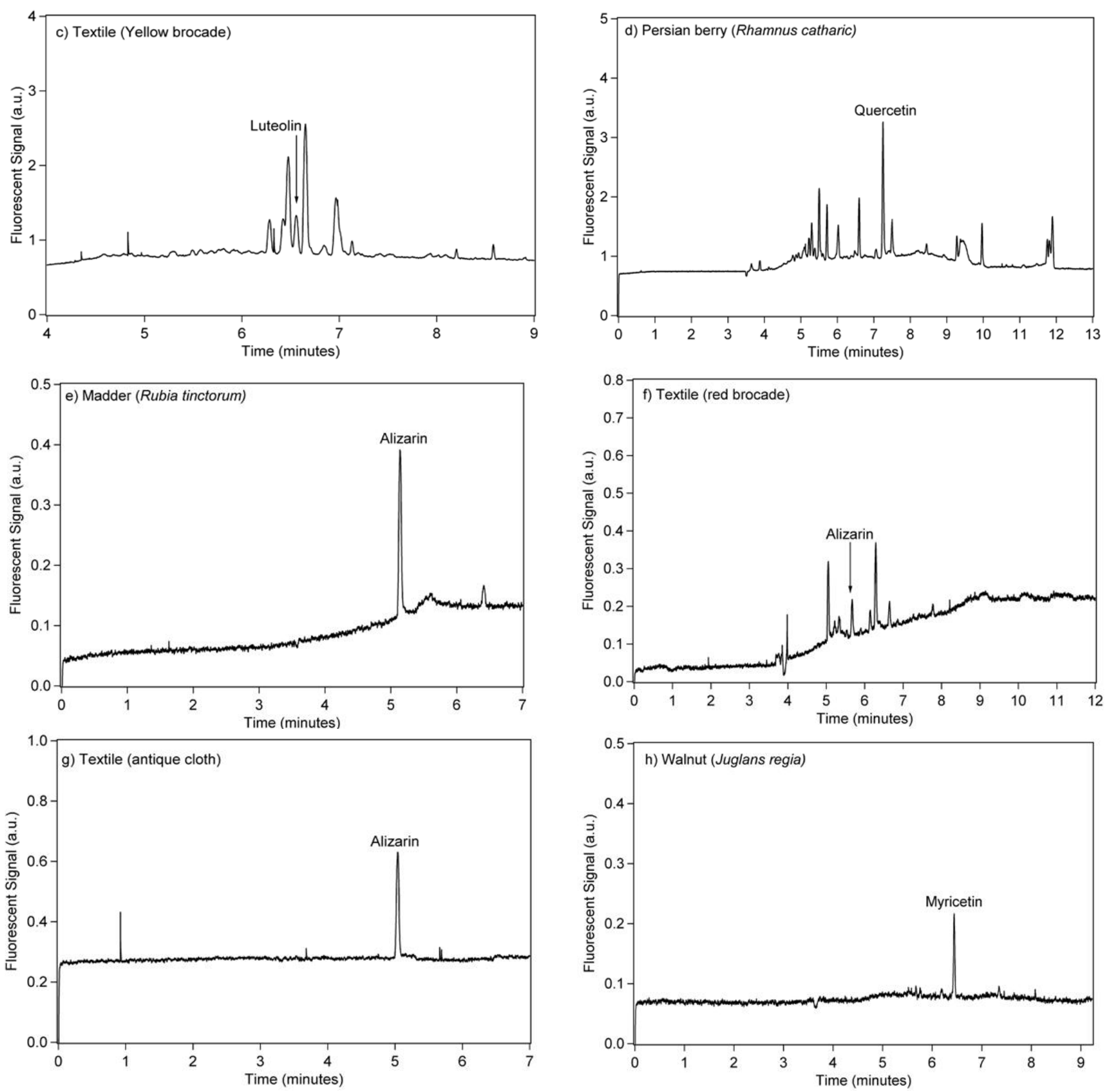

This approach was used for identifying peaks, as in most cases the migration time was affected noticeably by the sample matrix. Figure 6 shows the separation and peak identification of a number of natural dyes in a variety of samples, including plant material (Figure 6(d)), textiles that were dyed in the laboratory (Figure 6(b,e,h)), as well as in antique textile materials (Figure 6(c,f,g)). For some samples, peak identification was relatively straight forward, as there were not many peaks other than the target dye. This was the case for samples where alizarin was extracted from an antique cotton table cloth (Figure 6(g)) or from an antique red brocade (Figure 6(f)). Dyes, such as luteolin, that were extracted from wool (Figure 6(b)) also contained a number of peaks, which were likely associated with the a-keratin protein in these samples. Dyes that were extracted from plant material also contained a large number of peaks, which were easily separated from the dye. This was evident with quercetin extracted from Persian berries (Figure 6(d)). Overall, the peaks of the target dyes were well separated 
from the peaks of unidentified organic material associated with the sample, making the identification of the dyes relatively easy.

\section{Conclusions}

In this study, a number of experimental parameters were examined with the goal of improving separations and improving detection limits. When compared to voltage and the addition of organic modifiers, the $\mathrm{pH}$ of the buffer had a much greater effect on the separation of the dyes. Decreasing the pH from 9.24 to 8.0 changed the elution order of most flavonoid dyes. For some dyes, such as morin and quercetin, peaks were well resolved at $\mathrm{pH}=9.24$, but showed significant overlap at $\mathrm{pH}=8.0$. Decreasing the $\mathrm{pH}$ did not change the elution order of anthraquinone dyes; however, other beneficial effects were observed. In the case of emodin, decreasing the $\mathrm{pH}$ from 9.24 to 8.0 significantly improved the peak shape. In the case of purpurin, a small, rather broad peak was observed at $\mathrm{pH}=9.24$. At $\mathrm{pH}=8.0$, the peak shape of purpurin improved dramatically. Preliminary work in our lab indicates that purpurin is prone to photodecomposition at $\mathrm{pH}=9.24$. Decreasing the $\mathrm{pH}$ of the buffer to 8.0 improved the stability of purpurin significantly, which allowed it to be separated and detected using CE.

The most important advantage of using florescence for detecting dyes is the remarkably low detection limits that can be achieved. Adding organic modifiers and decreasing $\mathrm{pH}$ significantly affects both the separation properties of the $\mathrm{CE}$, as well as the fluorescence properties of some dyes. Using a lower $\mathrm{pH}$ buffer $(\mathrm{pH}=8.0)$ did not improve the separation or detection limits of all the dyes, but it significantly improved the peak shapes of anthraquinone dyes, such as purpurin. Therefore, in some cases, selecting a $\mathrm{pH}$ can be a compromise between a detectable fluorescence signal and the baseline separation of dyes.

\section{Acknowledgments}

Founding for this research was provided by the Natural Sciences and Engineering Research Council of Canada (NSERC). The University of Winnipeg is also acknowledged for its support of this research. D. Goltz and S. Ahmadi also acknowledge the University of Manitoba for its support of this work.

\section{Conflict of Interest}

The authors declare no conflict of interest.

\section{References}

1. Grierson, S. Dyeing and Dyestuffs; Shire Publications Ltd.: Bucks, UK, 1989.

2. Sanz Rodríguez, E.; Arteaga Rodríguez, A.; García Rodríguez, M.A.; del Egido, M.; Cámara, C.; Bailão, A.; Garcia, M. Identification of natural dyes in historical coptic textiles from the national archaeological museum of spain. E-Conserv. Mag. 2010, 15, 32-45.

3. Cardon, D. Natural Dyes. Sources, Tradition, Technology and Science; Archetype Publications: London, UK, 2007.

4. Bechtold, T.; Mussak, R. Handbook of Natural Colorants; Wiley: Chichester, UK, 2009. 
5. Peggie, D. The Development and Application of Analytical methods for the Identification of Dyes on Historical Textiles; University of Edinburgh: Edinburgh, UK, 2006.

6. Degano, I.; Ribechini, E.; Modugno, F.; Colombini, M.P. Analytical methods for the characterization of organic dyes in artworks and in historical textiles. Appl. Spectrosc. Rev. 2009, 44, 363-410.

7. Rie, E.R. Fluorescence of paint and varnish layers (Part I). Stud. Conserv. 1982, 27, 1-7.

8. Wallert, A. Unusual pigments on a greek marble basin. Stud. Conserv. 1995, 40, 177-188.

9. Miliani, C.; Romani, A.; Favaro, G. A spectrophotometric and fluorimetric study of some anthraquinoid and indigoid colorants used in artistic paintings. Spectrochim. Acta Part A 1998, 54, 581-588.

10. Clementi, C.; Miliani, C.; Romani, A.; Santamaria, U.; Morresi, F.; Mlynarska, K.; Favaro, G. In-situ fluorimetry: A powerful non-invasive diagnostic technique for natural dyes used in artefacts Part II. Identification of orcein and indigo in Renaissance tapestries. Spectrochim. Acta Part A 2009, 71, 2057-2062.

11. Low, M.J.D.; Baer, N.S. Application of infrared fourier transform spectroscopy to problems in conservation. Stud. Conserv. 1977, 22, 116-128.

12. Shearer, J.C.; Peters, D.C.; Hoepfner, G.; Newton, T. FT-IR in the service of art conservation. Anal. Chem. 1983, 55, 874A-880A.

13. Gillard, R.D.; Hardman, S.M.; Thomas, R.G.; Watkinson, D.E. The detection of dyes by FTIR microscopy. Stud. Conserv. 1994, 39, 187-192.

14. Edwards, H.G.M. Illumination of a mediaeval mystery: The FT-Raman spectroscopic analysis of red pigment from a mediaeval corbel in the church st clement of rome, fiskerton. J. Mol. Struct. 2003, 661, 271-277.

15. Edwards, H.G.M.; Villar, S.E.J.; Eremin, K.A. Raman spectroscopic analysis of pigments from dynastic egyptian funerary artefacts. J. Raman Spectrosc. 2004, 35, 786-795.

16. Kharbade, B.V.; Agrawal, O.P. Analysis of natural dyes in indian historic textiles. Stud. Conserv. 1988, 33, 1-8.

17. Scott, D.; Khandekar, N.; Schilling, M.; Turner, N.; Taniguchi, Y.; Khanjian, H. Technical examination of a fifteenth-century German illuminated manuscript on paper: A case study in the identification of materials. Stud. Conserv. 2001, 46, 93-108.

18. Wouters, J.; Verhecken, A. The coccid insect dyes: HPLC and computerized diode-array analysis of dyed yarns. Stud. Conserv. 1989, 34, 189-200.

19. Colombini, M.P.; Carmignani, A.; Modugno, F.; Frezzato, F.; Olchini, A.; Brecoulaki, H.; Vassilopoulou, V.; Karkanas, P. Integrated analytical techniques for the study of ancient greek polychromy. Talanta 2004, 63, 839-848.

20. Domenech-Carbo, M.; Casas-Catalan, M.; Domenech-Carbo, A.; Mateo-Castro, R.; Gimeno-Adelantado, J.; Bosch-Reig, F. Analytical study of canvas painting collection from the basilica de la virgen de los desamparados using SEM/EDX, FT-IR, GC and electrochemical techniques. Fresenius J. Anal. Chem. 2001, 369, 571-575.

21. Puchalska, M.; Orlinska, M.; Ackacha, M.; Polec-Pawlak, K.; Jarosz, M. Identification of anthraquinone coloring matters in natural red dyes by electrospray mass spectrometry coupled to capillary electrophoresis. J. Mass Spectrom. 2003, 38, 1252-1258. 
22. Surowiec, I.; Pawelec, K.; Rezeli, M.; Kilar, F.; Trojanowicz, M. Capillary electrophoretic determination of main components of natural dyes with ms detection. J. Sep. Sci. 2008, 31, 2457-2462.

23. Trojanowicz, M.; Wojcik, L.; Urbaniak-Walczak, K. Identification of natural dyes in historical coptic textiles by capillary electrophoresis with diode array detection. Chem. Anal. 2003, 48, 607-620.

24. Maguregui, M.I.; Alonso, R.M.; Barandiaran, M.; Jimenez, R.M.; Garcia, N. Micellar electrokinetic chromatography method for the determination of several natural red dyestuff and lake pigments used in art work. J. Chromatogr. A 2007, 1154, 429-436.

25. Lopez-Montes, A.; Blanc Garcia, R.; Espejo, T.; Huertas-Perez, J.F.; Navalon, A.; Luis Vilchez, J. Simultaneous identification of natural dyes in the collection of drawings and maps from the royal chancellery archives in Granada (Spain) by CE. Electrophoresis 2007, 28, 1243-1251.

26. Goltz, D.M.; Ahmadi, S.; Absalan, G.; Craig, D.B. Separation of historical dyes using capillary electrophoresis with laser-induced fluorescence detection. J. Liq. Chromatogr. Relat. Technol. 2012, 35, 2054-2065.

27. Colombini, M.P.; Andreotti, A.; Baraldi, C.; Degano, I.; Łucejko, J.J. Colour fading in textiles: A model study on the decomposition of natural dyes. Microchem. J. 2007, 85, 174-182.

28. Craig, D.; Arriaga, E.; Banks, P.; Zhang, Y.; Renborg, A.; Palcic, M.; Dovichi, N. Fluorescence-based enzymatic assay by capillary electrophoresis laser-induced fluorescence detection for the determination of a few beta-galactosidase molecules. Anal. Biochem. 1995, 226, 147-153.

29. Rice, C.L.; Whitehead, R. Electrokinetic flow in a narrow cylindrical capillary. J. Phys. Chem. 1965, 69, 4017-4024.

30. Jorgenson, J.W.; Lukacs, K.D. Capillary zone electrophoresis. Science 1983, 222, 266-272.

31. McGhie, T.K. Analysis of sugarcane flavonoids by capillary zone electrophoresis. J. Chromatogr. 1993, 634, 107-112.

32. Ng, C.L.; Ong, C.P.; Lee, H.; Li, S.F.Y. Systematic optimization of micellar electrokinetic chromatographic-separation of flavonoids. Chromatographia 1992, 34, 166-172.

33. McGhie, T.K.; Markham, K.R. Separation of flavonols by capillary electrophoresis-The effect of structure on electrophoretic mobility. Phytochem. Anal. 1994, 5, 121-126.

34. Delgado, C.; Tomasbarberan, F.A.; Talou, T.; Gaset, A. Capillary electrophoresis as an alternative to HPLC for determination of honey flavonoids. Chromatographia 1994, 38, 71-78.

35. Khaled, M.Y.; Anderson, M.R.; McNair, H.M. Micellar electrokinetic capillary chromatography of pungent compounds using simultaneous online ultraviolet and electrochemical detection. J. Chromatogr. Sci. 1993, 31, 259-264.

36. Jimidar, M.; Hamoir, T.P.; Foriers, A.; Massart, D.L. Comparison of capillary zone electrophoresis with high-performance liquid chromatography for the determination of additives in foodstuffs. J. Chromatogr. A 1993, 636, 179-186.

37. Terabe, S. Selectivity manipulation in micellar electrokinetic chromatography. J. Pharm. Biomed. Anal. 1992, 10, 705-715.

38. Kum, S.; Jagasia, R.; Haldar, B.C. Acid dissociation constants of morin in ethanol-water mixture. J. Indian Chem. Soc. 1963, 40, 287-292. 
39. Tyukavkina, N.A.; Pogodaeva, N.N. Ultraviolet-absorption of flavonoids. VIII. Ionization-constants of kempferol and quercetin. Khim. Prirod. Soedin. 1975, 6, 708-711.

40. Herrero-Martinez, J.; Sanmartin, M.; Roses, M.; Bosch, E.; Rafols, C. Determination of dissociation constants of flavonoids by capillary electrophoresis. Electrophoresis 2005, 26, 1886-1895.

41. Harris, D.C. Quantitative Chemical Analysis; W.H. Freeman and Company: New York, NY, USA, 2003.

(C) 2013 by the authors; licensee MDPI, Basel, Switzerland. This article is an open access article distributed under the terms and conditions of the Creative Commons Attribution license (http://creativecommons.org/licenses/by/3.0/). 